\title{
Obstetric Risk and Outcomes of Teenage Pregnancy in a University Teaching Hospital, North-Central, Nigeria
}

\author{
Bernard Terkimbi Utoo $^{* * \mathbb{C}}$, Unazi Elias Ubah' ${ }^{1}$ Peter Onche Eka ${ }^{1}$
}

\begin{abstract}
Objectives: Teenage pregnancy has generated much interest in Obstetrics practice due to increasing risk to the baby and the mother. In this regard, this study was done to ascertain its incidence, obstetric risk, and outcomes.

Materials and Methods: This study reviewed the obstetric data sheets of all teenage pregnancies managed between January 2013 and December 2017 at the Benue State University Teaching Hospital, Makurdi, North -Central, Nigeria.

Results: Teenage deliveries included 43 cases constituting $2.06 \%$ of the total 2084 deliveries within the period. The mean age (SD) was $17.88( \pm 1.77)$ years. The commonest antenatal complications were malaria $(39.5 \%)$, anaemia $(37.2 \%)$, and hypertension in pregnancy $(20.9 \%)$. The augmentation of labour was done for 16 parturient mothers $(37.2 \%)$ and $16.3 \%$ had the induction of labour. The caesarean section rate was $16.3 \%$ and it was mostly related to obstructed labour (47.1\%). In addition, episiotomy was done in $11.6 \%$ of parturient mothers and $46.5 \%$ had perineal tear. There were 37 live births out of which, 6 cases were neonatal admissions and 6 other cases were perinatal deaths. Finally, the perinatal mortality rate among the teenage deliveries was 139.5 per 1000 .

Conclusions: The incidence of teenage births was $2.06 \%$ with associated obstetric risks and adverse pregnancy outcomes necessitating improved obstetric care during pregnancy and delivery.

Keywords: Maternal mortality, Obstetrics, Perineal tear, Primigravidae, Teenage pregnancy
\end{abstract}

\section{Introduction}

Inadequate social support and poor maternal well-being have made teenage pregnancy a topical public health issue. Pregnancies occurring among girls who are under the age of 20 years is defined by the World Health Organization (WHO) as teenage pregnancies (1). This constitutes about 21.8 per 1000 deliveries (2.18\%) in Nigeria (2$5)$. The reported incidence in Africa is about $18.6 \%$ (6) while it is nearly 143 per 1000 deliveries $(14.3 \%)$ in some Sub-Saharan Africa and decreases to about 2.9 per 1000 deliveries in South Korea $(5,7)$. In the United States, the incidence is approximately 53 girls (15-19 years) per 1000 deliveries and this age group represents about 13\% of all live births (7). An early sexual debut which may be influenced by poverty, peer pressure, lack of education, substance abuse, or risky cultural sexual behaviours, and the like could be responsible for teenage pregnancy (810). On the other hand, it is believed that the likelihood of an early sexual debut reduces by an improvement in the education level of the girls, live within families with stable incomes, a better parent-child relationship, and diligent supervision, and there is also a decrease in risky sexual behaviour among them thus minimizing teenage pregnancy (10).

Psychological, emotional, and social problems resulting in suicide among these young girls are some of the challenges that have been widely discussed as well. Some of the girls are abandoned by their sexual partners and parents felt extremely disappointed by the behaviour of their wards (11-15). Several studies have shown that pregnancies in teenage mothers are more at risk to end before term to the delivery of low birth weight babies with an increased risk of neonatal mortality (16-18). Other outcomes include a low Apgar score and congenital malformation. For the mother, conditions such as anemia, malaria, urinary tract infections, poor maternal weight gain, pregnancy-induced hypertension, and sexually transmitted disease are reported to be common problems. Other conditions include prolonged labour, obstructed labour, increased neonatal mortality rate, renal complications, and maternal mortality (19-25).

Up to date, there is a paucity of documented studies on a relevant matter such as obstetrics risks and the outcomes of teenage delivery in our environment. In this respect, this study was designed to ascertain the incidence, the obstetric risk, and the outcome of teenage delivery. This information is expected to assist in our health education campaigns among young people.

\section{Materials and Methods}

It was a descriptive cohort study of all teenage deliveries managed in the Teaching Hospital of Benue State University between January 2013 and December 2017. The Delivery Register and Obstetric Data Sheets (a detailed record 


\section{Key Message}

- The obstetric risk and unfavorable outcomes observed in the study should serve as an impetus to stalk holders towards the efforts of preventing child marriage and reduction in teenage pregnancies. Girl child education, sexual health education, contraceptive usage and economic empowerment is key.

- Provision of expert maternity care with special attention to this high risk group should be prioritized.

sheet of every obstetric case kept by the Department of Obstetrics and Gynaecology) were retrieved and related information was extracted accordingly. The sample size was chosen based on the reported incidence of teenage pregnancy as $1.6 \%$ in a study done in Jos, which is a city in North Central Nigeria (5) using the Fisher's formula.

$\mathrm{N}=\mathrm{Z}^{2} \mathrm{p} \mathrm{q} / \mathrm{d}^{2}$ :

$\mathrm{N}=$ Minimum sample size;

$\mathrm{Z}=$ Standard normal deviate corresponding to the level of significance at $95 \%=1.96, P=0.16, q(1-p)=0.984$, and $\mathrm{d}=$ level of precision set at $5 \%, \mathrm{~N}=24$.

A total of 43 was accepted to increase the statistical power of the results. The extracted information included age, marital status, parity, antenatal complications such as anaemia, pre-eclampsia, eclampsia, gestational age at delivery, route of delivery, labour duration, birth weight, APGAR scores, blood loss, and neonatal admission. The data were subjected to appropriate statistical analysis through SPSS software, version 25.0. Variables were represented in simple frequencies and percentages. The strength of the association was estimated using the chisquare test, and statistical significance was set at $P$ values $<0.05$ at a $95 \%$ confidence interval. All nulliparous and multiparous women aged below 20 years during the review period underwent an investigation. Those excluded from the study were women who delivered at home. The categorization of the maternal age group was 14-15 years, 16-17 years, and 18-19 years. The birth outcomes were infants at $<37$ weeks, birth weights below $2.5 \mathrm{~kg}$, Apgar score $<5$ at 5 minutes, and neonatal deaths among others.

\section{Results}

Out of 2084 deliveries, 43 of these parturient mothers were 19 years and below. From this number, the incidence of teenage mothers was $2.06 \%$. Their age ranged between 14 and 19 years. The mean age $( \pm$ SD) was $17.88( \pm 1.77)$ years. Out of these 43 teenage deliveries, 16 (37.2\%) and $27(62.8 \%)$ cases were single and married, respectively. The majority of the parturient $(76.7 \%)$ had secondary school education while the minority $(9.3 \%)$ were still in higher institutions during the period of delivery. The minority, namely, $11.6 \%$ of parturient were gainfully employed while the majority $(88.4 \%)$ of them were unemployed (Table 1). Most teenage mothers (86\%) were primigravida as at the time of delivery while $14.0 \%$ of them were multigravida (Table 1). Seventeen (39.5\%) parturient mothers had malaria (treated with positive malaria parasite on the blood film) during the antenatal period. Anaemia was considered as the packed cell volume less than $30 \%$ accounted for $37.2 \%$ and hypertensive disease (eclampsia/preeclampsia) accounted for $20.9 \%$. Six $(14.0 \%)$ parturient mothers had a urinary tract infection. Other cases including rhesus negative mothers, retroviral disease, intrauterine fetal death, and preterm labour accounted for $23.3 \%$. Other complications such as intrauterine growth restriction, hepatitis, and the preterm rupture of the membrane were less probable among the cases (Table 2). About 38 (88.4\%) of adolescent mothers had at least one antenatal complication. Eleven teenage mothers $(25.6 \%)$ had preterm delivery with a gestational age of less than 37 weeks (Table 3 ). The caesarean section rate was $16.3 \%$. Out of the babies delivered by teenage mothers, $36(83.7 \%)$ cases had normal birth weight.

Table 1. Demographic Variables of Teenage Mothers

\begin{tabular}{lcc}
\hline Variable & No. & $\%$ \\
\hline Age & 1 & 2.3 \\
$14-15$ & 8 & 18.6 \\
$16-17$ & 34 & 79.1 \\
$18-19$ & & \\
Marital status & 16 & 37.2 \\
Single & 27 & 62.8 \\
Married & & \\
Educational status & 6 & 14.0 \\
$\quad$ Primary & 33 & 76.7 \\
Secondary & 4 & 9.3 \\
Tertiary & & \\
Occupation & 5 & 11.6 \\
Employed & 38 & 88.4 \\
$\quad$ Unemployed & & \\
Parity & 37 & 86.0 \\
Primigravida & 6 & 14.0 \\
Multigravida & & \\
Booking status & 29 & \\
Yes & 14 & \\
No & & \\
\hline & &
\end{tabular}

Table 2. Obstetric Risk of Teenage Pregnancy in the Study

\begin{tabular}{lcc}
\hline Variable & No. & \% \\
\hline Malaria & 17 & 39.5 \\
Anemia & 16 & 37.2 \\
Hypertensive disorders & 9 & 20.9 \\
Urinary tract infection & 6 & 14.0 \\
IUGR & 2 & 4.7 \\
Hepatitis & 2 & 4.7 \\
PROM & 1 & 2.3 \\
Others & 10 & 23.3 \\
Total & 43 & 100.0 \\
\hline
\end{tabular}

Note. IUGR: Intrauterine growth retardation; PROM: Preterm premature rupture of the membranes. 
Table 3. Delivery Outcomes of Teenage Pregnancies in the Study

\begin{tabular}{|c|c|c|}
\hline Variable & No. & $\%$ \\
\hline \multicolumn{3}{|c|}{ Gestational age at delivery } \\
\hline$<37$ & 11 & 25.6 \\
\hline $37-40$ & 27 & 62.8 \\
\hline $41-42$ & 3 & 7.0 \\
\hline$>42$ & 2 & 4.7 \\
\hline \multicolumn{3}{|l|}{ Mode of delivery } \\
\hline Vaginal & 36 & 83.7 \\
\hline Caesarean & 7 & 16.3 \\
\hline \multicolumn{3}{|c|}{ Duration of labour } \\
\hline$<12$ & 40 & 93.0 \\
\hline$>12$ & 3 & 7.0 \\
\hline \multicolumn{3}{|l|}{ Blood loss } \\
\hline$<500$ & 39 & 90.7 \\
\hline$>500$ & 4 & 7.0 \\
\hline \multicolumn{3}{|l|}{ Birth weight } \\
\hline $1-1.49$ & 3 & 7.0 \\
\hline $1.5-2.45$ & 4 & 9.3 \\
\hline $2.5-3.99$ & 36 & 83.7 \\
\hline \multicolumn{3}{|c|}{ Types of initiation of labour } \\
\hline Spontaneous & 18 & 41.9 \\
\hline Augmentation & 16 & 37.2 \\
\hline Induction & 9 & 20.9 \\
\hline \multicolumn{3}{|c|}{ Neonatal admission } \\
\hline Yes & 6 & 14.0 \\
\hline No & 37 & 86.0 \\
\hline \multicolumn{3}{|l|}{ Genital injury } \\
\hline Episiotomy & 18 & 41.9 \\
\hline Perineal tear & 5 & 11.6 \\
\hline Intact perineum & 20 & 46.5 \\
\hline
\end{tabular}

Sixteen (37.2\%) parturient mothers were augmented in labour which made the augmentation rate to be $37.2 \%$. Eighteen women (41.9\%) had an episiotomy and 5 (11.6\%) cases had a perineal tear (Table 3). The indications for caesarean section were obstructed labour (28.57\%), Pre-eclampsia/eclampsia (28.57\%), Breech presentation (28.57\%) and fetal distress (14.29\%) (Table 4). Pregnancies that were at advance gestational age were less likely to be augmented (Table 5). Finally, there were 6 stillbirths, and the total perinatal death was 6 (13.95\%) (Table 6) .

\section{Discussion}

The incidence of teenage delivery in this study was $2.06 \%$, which is close to the report of other studies in Nigeria done in Nnewi, Ibadan, and Ilorin where the incidence was found to be $2.18 \%, 2.4 \%$, and $1.93 \%$, respectively $(1-4,26,27)$. It was slightly higher (1.6\%) than the report from Jos (5) but lower than $9.6 \%$ reported in Uyo south-south Nigeria (5). However, it is extremely lower than the incidence of $18.6 \%$ and $14.3 \%$ reported for Africa and sub-Saharan Africa, respectively (6). The incidence (2.06\%) reported in this study was also found to be lower than the $5.3 \%$ incidence reported in a study done in the United States (7). Therefore, we can appreciate the variation regionally within Nigeria, continentally, and at international levels.
Table 4. Indication for Caesarean Section

\begin{tabular}{lcc}
\hline Variables & No. & $\%$ \\
\hline Obstructed labour & 2 & 28.57 \\
Fetal distress & 1 & 14.29 \\
Eclampsia/preeclampsia & 2 & 28.57 \\
Malpresentation (breach) & 2 & 28.57 \\
Total & 7 & 100 \\
\hline
\end{tabular}

Table 5. Association Between the Type of the Initiation of Labour and Gestational Age at Delivery

\begin{tabular}{lccccc}
\hline \multirow{2}{*}{ Labour Initiation } & \multicolumn{5}{c}{ Gestational Age } \\
\cline { 2 - 6 } & $<\mathbf{3 7}$ & $\mathbf{3 7 - 4 0}$ & $\mathbf{4 1 - 4 2}$ & $\mathbf{> 4 2}$ & Total \\
\hline Spontaneous & 5 & 11 & 1 & 1 & 18 \\
Augmentation & 0 & 16 & 0 & 0 & 16 \\
Induction & 6 & 0 & 2 & 1 & 9 \\
Total & 11 & 27 & 3 & 2 & 43 \\
\hline
\end{tabular}

Note. $\chi^{2}=37.930 ; P<0.001$.

Table 6. Summary of Perinatal Outcomes

\begin{tabular}{lcc}
\hline Outcome & No. & $\%$ \\
\hline Live birth & 37 & 86.05 \\
Fresh still birth & 3 & 6.98 \\
Macerated still birth & 3 & 6.98 \\
APGAR score $\leq 5$ & 0 & 0 \\
NICU admission & 6 & 13.95 \\
Low birth weight & 7 & 16.28 \\
Perinatal mortality & 6 & 13.95 \\
\hline
\end{tabular}

Note. NICU: Neonatal intensive care unit.

This low incidence in Nigeria may be explained by a positive changing attitude of the Nigerian society toward the education of the female child. It is also possible that many of the young girls terminated their pregnancies early. The intense public health campaigns and the promotion of contraceptive uptake could also explain the low incidence. The role of increasing religious activities discouraging sex in unmarried people may also play a role in this regard. Similarly, cultural and traditional prohibitions to early risky sexual behaviors in parts of Nigeria could have also contributed to lower figures.

A large proportion (37.2\%) of this group of mothers were unmarried. This expected finding is in line with the results of other studies $(4,28-30)$. The reason is that most pregnancies were unplanned. Most young mothers had a secondary level of education and were unemployed, representing the likelihood that they were not ready for a pregnancy at the time of its occurrence. They are usually more likely to have academic difficulties, high dropout rates, financial constraints, and a lack of economic empowerment (15). Surprisingly, $67.4 \%$ of these patients had antenatal care against the backdrop of their expected low socio-economic status. This may be the result of the increasing antenatal use in the general population. Consistent campaigns toward promoting antenatal care attendance in Nigeria are 
yielding positive results as demonstrated by an increase in the uptake of antenatal services by pregnant women. It is reported in the Nigerian Demographic Health Survey that the proportion of women receiving antenatal care from skilled providers has steadily increased from $58 \%$ to $67 \%$ since 2008.

Anaemia is one of the most common antenatal complications which has occurred in $37.2 \%$ of patients. This is comparable to the findings of other studies $(13,28,29)$, demonstrating an incidence rate of $25 \%-60 \%$. First, this could be because as teenagers and primigravida, they may have had difficulty with compliance on routine and regular intake of haematinics and other nutritional measures despite antenatal care clinic advice. In addition, the majority of teenagers were not gainfully employed thus the cost of care could have been a matter of concern as well. Further, this study was done in a malaria-endemic region and thus malaria, which is the most common complication in the antenatal period (39.5\%), is not an unusual finding and this may be connected with the fact that the majority of them are primigravida with the highest incidence of malaria in pregnancy. Immunity against malaria in primigravidae is not yet developed, leading to greater susceptibility in this group of patients. Hypertensive disease (i.e., pre-eclampsia and eclampsia) incidence (20.9\% per 100 deliveries), which contradicts that of the general population $(19,20)$ and thus it is fair to agree with the increased incidence of preeclampsia and eclampsia reported by earlier studies $(13,21)$. Preeclampsia is considered as a disease of primigravidae. The augmentation of labour was as high as $37.2 \%$. This is not surprising because the majority of girls were primigravidae whose labour was known to be complicated with uterine inertia as demonstrated by the studies of O' Driscol in Dublin. Most clinicians do favor routine augmentation of labour in primigravidae (30-33).

The caesarean section rate of $16.3 \%$ for teenage deliveries was lower than the rate $(19.5 \%)$ reported in the same hospital where this study was done among the general obstetric patients $(26,31)$. This could be attributed to the fact that those who attended the antenatal clinic were more than those who did not attend, resulting in a higher vaginal delivery rate. Nonetheless, obstructed labour resulting from unattained full pelvic dimensions at this young age among other major indications for a caesarean section such as eclampsia with an unfavorable cervix, fetal distress, and malpresentation/malposition were responsible for the caesarean section rate in this study. This rate at a young age is higher than the one reported by another study among adolescent pregnant women (23).

The rate of preterm and low birth weight deliveries found in this age corroborates that demonstrated by other studies and is attributed to low pre-pregnancy weight, poor nutrition in the antenatal period, and the immaturity of the uterine blood supply $(3,13,22-29)$. The immaturity of blood supply encourages the sub-clinical infection that produces infection and preterm delivery $(25,26)$. The high prevalence of birth weight less than $2.5 \mathrm{~kg}(16.28 \%)$ was supported by a study by Thato et al (34) and Mahavarka et al (35).

Episiotomy was done for $41.9 \%$ of all teenage parturient while $11.6 \%$ of them had a perineal tear. These findings do not match with the findings of Ugianskiene et al, indicating that $4.5 \%$ of parturient mothers had an episiotomy and $52.8 \%$ of them had a perineal tear. This difference occurred because a perineal tear was prevented and reduced by offering episiotomy to parturient mothers at the risk of a perineal tear after careful evaluations in the study center (36). Once the perineum appeared tight and threatened to tear, the accoucheurs had a low threshold for episiotomy as a safety measure to avoid an ugly tear that would either be life-threatening or cause a long-term obstetric and gynecological problem.

Perinatal mortality (6 in 43 teenage deliveries) is high, but it was also reported in (22). The risk of the increased neonatal mortality rate is about 3 times that of adult women. Preeclampsia, eclampsia, renal disease, anaemia, infections such as malaria, preterm deliveries, obstructed labour, and common complications in teenage pregnancies could be responsible for stillbirths.

The children of the adolescent mother also have an increased share of excess risk like the mother. These are early sexual debut, academic challenge, behavioral disorder, delinquency, and becoming an adolescent parent $(10,15)$.

Although maternal death was not reported, the risk of increased morbidity in this age group of mothers is a reflection of various risks enunciated above. The clinical usage of the results of this study will go a long way in helping healthcare providers with the necessary information that can be used during health talks, enlightenment campaigns, workshops, and advocacy to promote the health of teenagers in our societies. It will also build the capacity of birth attendance to effectively combat these obstetric risks and the unfavourable outcomes of teenage deliveries.

The number of included patients in this study was obviously small. Therefore, we recommend a larger clinical controlled study on the obstetric performance of teenagers to confirm these findings.

\section{Conclusions}

Although the incidence of teenage delivery is comparable to and even lower than reports in other studies, deliveries among these age group still have significant obstetric risks and unfavourable pregnancy outcomes necessitating improved obstetric care during pregnancy and delivery.

\section{Recommendation}

We recommend that the government should provide more educational facilities to engage adolescents in academic activities and to empower women to cater more to their 
teenage daughters. Contraceptive services should also be made more accessible to the teenage group to prevent most of these early pregnancies. Eventually, the government should provide and expand well-equipped pregnant teenagers' friendly health centers to offer quality antenatal care to this age group.

\section{Authors' Contribution}

BTU conceived the research, designed the study and wrote the initial draft of the manuscript. UEU collected the data and entered it into the statistical software and contributed to the draft of the manuscript and POE did data analysis and interpretation. All authors agreed to the final manuscript.

\section{Conflict of Interests}

The authors declare no conflict of interest.

\section{Ethical Issues}

Although it was a retrospective study, the Ethics Committee of the hospital approved it.

\section{Financial Support}

There was no financial support received from any agency or institution for this study.

\section{Acknowledgments}

We appreciate all the resident doctors and consultants in the department for their cooperation and input into the study from conception, design, data collection, and write up of the manuscript. Particular thanks go to Dr. Usha Anenga for data analysis and Mrs. Cecilia Unazi for her encouragement.

\section{References}

1. Socolov DG, lorga M, Carauleanu A, et al. Pregnancy during adolescence and associated risk. An 8-year hospital-based cohort study (2007-2014) in Romania, the country with the highest rate of teenage pregnancy in europe. BioMed Res Int. 2017;2017:9205016. doi:10.1155/2017/9205016

2. Taffa N. A comparison of pregnancy and child health outcomes between teenage and adult mothers in the slums of Nairobi, Kenya. Int J Adolesc Med Health. 2003;15(4):321329. doi:10.1515/ijamh.2003.15.4.321

3. Rehan N, Sani S. Obstetric behavior of Hausa women. J Obstet Gynaecol East Cent Africa. 1986;5:21-25.

4. Treffers PE, Olukoya AA, Ferguson BJ, Liljestrand J. Care for adolescent pregnancy and childbirth. Int J Gynaecol Obstet. 2001;75(2):111-121. doi:10.1016/s0020-7292(01)00368-x

5. Igwegbe AO, Udigwe GO. Teenage pregnancy: still an obstetric risk. J Obstet Gynaecol. 2001;21(5):478-481. doi:10.1080/01443610120072027

6. Sanghvi HC, Mati JK, Aggawal VP, Lucas S, Corkhill R. Outcome of pregnancy in teenage mothers in Nairobi, Kenya. J Obstet Gynaecol East Cent Africa. 1983;2(4):134-139.

7. Treffers PE. [Teenage pregnancy, a worldwide problem]. Ned Tijdschr Geneeskd. 2003;147(47):2320-2325.

8. Mayor S. Pregnancy and childbirth are leading causes of death in teenage girls in developing countries. BMJ. 2004;328(7449):1152. doi:10.1136/bmj.328.7449.1152-a

9. Centers for Disease Control and Prevention (CDC). Few Teens Use the Most Effective Types of Birth Control. https://www. cdc.gov/media/releases/2015/p0407-teen-pregnancy.html. Accessed July 26, 2019.
10. Klein JD. Adolescent pregnancy: current trends and issues. Pediatrics. 2005;116(1):281-286. doi:10.1542/peds.20050999

11. Otoide VO, Oronsanye F, Okonofua F. Why Nigerian adolescents seek abortion rather than contraception: evidence from focus-group discussions. Int Fam Plan Perspect. 2001;27(2):77-81.

12. Hofferth SL, Reid L, Mott FL. The effects of early childbearing on schooling over time. Fam Plann Perspect. 2001;33(6):259267.

13. Irvine $\mathrm{H}$, Bradley $\mathrm{T}$, Cupples $\mathrm{M}$, Boohan $\mathrm{N}$. The Implications of teenage pregnancy and motherhood for primary health care: Unresolved issues. Br J Gen Pract. 1997;47:323-326.

14. Mutihir JT, Maduka WE. Comparison of pregnancy outcome between teenage and older primigravidae in Jos University Teaching Hospital, Jos, North-Central Nigeria. Ann Afr Med. 2006;5(2):101-106.

15. Okpani AO, Ikimalo J, John CT, Briggs ND. Teenage pregnancy. Trop J Obstet Gynecol. 1995;12(1):34-36.

16. Gilbert W, Jandial D, Field N, Bigelow P, Danielsen B. Birth outcomes in teenage pregnancies. J Matern Fetal Neonatal Med. 2004;16(5):265-270. doi:10.1080/14767050400018064

17. Gortzak-Uzan L, Hallak M, Press F, Katz M, Shoham-Vardi I. Teenage pregnancy: risk factors for adverse perinatal outcome. J Matern Fetal Med. 2001;10(6):393-397. doi:10.1080/714904371

18. Igwegbe AO, Udigwe GO. Teenage pregnancy: still an obstetric risk. J Obstet Gynaecol. 2001;21(5):478-481. doi:10.1080/01443610120072027

19. Loto OM, Ezechi OC, Kalu BK, Loto A, Ezechi L, Ogunniyi SO. Poor obstetric performance of teenagers: is it age- or quality of care-related? J Obstet Gynaecol. 2004;24(4):395-398. doi:10. 1080/01443610410001685529

20. Banerjee B, Pandey G, Dutt D, Sengupta B, Mondal M, Deb S. Teenage pregnancy: a socially inflicted health hazard. Indian J Community Med. 2009;34(3):227-231. doi:10.4103/09700218.55289

21. Pal A, Gupta KB, Randhawa I. Adolescent pregnancy: a high risk group. J Indian Med Assoc. 1997;95(5):127-128.

22. United Nation Population Fund. Early Marriage in Nigeria. http://www.nigeria.unfpa.org/nigeriachild.html. Accessed February 21, 2020.

23. National Population Commission (NPC) Nigeria, ICF International. Nigeria Demographic and Health Survey Abuja Nigeria. Rock Villa, Maryland, USA: NPC, ICF International; 2014.

24. JS Owoseni, LI Jegede, Ibikunle AM. Socio-economic status and utilization of healthcare facilities in rural Ekiti, Nigeria. Stand Res J Med Med Sci. 2014;2(1):1-43.

25. Ujah IA, Aisien OA, Mutihir JT, Vanderjagt DJ, Glew RH, Uguru VE. Maternal mortality among adolescent women in Jos, North-Central, Nigeria. J Obstet Gynaecol. 2005;25(1):36. doi:10.1080/01443610400023395

26. Omole-Ohonsi A, Attah RA. Obstetric outcome of teenage pregnancy in Kano, North-Western Nigeria. West Afr J Med. 2010;29(5):318-322. doi:10.4314/wajm.v29i5.68252

27. Jimoh AS, Abdul IF. Outcome of teenage pregnancies in Ilorin, Nigeria. Trop J Obstet Gyneacol. 2004;21(1):27-31. doi:10.4314/tjog.v21i1.14459

28. Sharma AK, Verma K, Khatri S, Kannan AT. Pregnancy in adolescents: a study of risks and outcome in Eastern Nepal. Indian Pediatr. 2001;38(12):1405-1409. 
29. Chandra PC, Schiavello HJ, Ravi B, Weinstein AG, Hook FB. Pregnancy outcomes in urban teenagers. Int J Gynaecol Obstet. 2002;79(2):117-122. doi:10.1016/s0020-7292(02)00240-0

30. Berkowitz GS, Marcus M. Adolescence and pregnancy outcome. Ann Epidemiol. 1992;2(5):755-757. doi:10.1016/1047-2797(92)90020-q

31. Hembah-Hilekaan SK, Ojabo O, Idogah S. Caesarean section rate in a tertiary hospital in Makurdi, North-Central Nigeria. Gen Med (Los Angel). 2015;3(3):183. doi:10.4172/23275146.1000183

32. Gardosi J, Vanner T, Francis A. Gestational age and induction of labour for prolonged pregnancy. Br J Obstet Gynaecol. 1997; 104(7):792-797. doi:10.1111/j.1471-0528.1997.tb12022.x

33. Fagbamigbe $\mathrm{AF}$, Idemudia ES. Wealth and antenatal care utilization in Nigeria: policy implications. Health Care Women Int. 2017;38(1):17-37. doi:10.1080/07399332.2016 .1225743

34. Thato S, Rachukul S, Sopajaree C. Obstetrics and perinatal outcomes of Thai pregnant adolescents: a retrospective study. Int J Nurs Stud. 2007;44(7):1158-1164. doi:10.1016/j. ijnurstu.2006.05.016

35. Mahavarkar SH, Madhu CK, Mule VD. A comparative study of teenage pregnancy. J Obstet Gynaecol. 2008;28(6):604-607. doi:10.1080/01443610802281831

36. Ugianskiene A, Ledertoug S, Murrekilde P, Bor P. Teenage pregnancies: obstetric and neonatal outcomes at a Danish Regional hospital. J Women's Health Care. 2015;4(7):283. doi:10.4172/2167-0420.1000283.

(C) 2021 The Author(s); This is an open-access article distributed under the terms of the Creative Commons Attribution License (http:// creativecommons.org/licenses/by/4.0), which permits unrestricted use, distribution, and reproduction in any medium, provided the original work is properly cited. 